\title{
REVISITANDO A REGIONALIZAÇÃO DE VAZÕES NA REGIÃO DO MÉDIO PARANAPANEMA NO ESTADO DE SÃO PAULO: UTILIZAÇÃO DE CURVAS DE PERMANÊNCIA EM MICROBACIAS HIDROGRÁFICAS
}

\author{
César de Oliveira Ferreira SILVA \\ Rodrigo Lilla MANZIONE
}

\begin{abstract}
RESUMO
A escassez de informações para embasar a tomada de decisão no gerenciamento de recursos hídricos é uma das principais limitações ao uso adequado desses recursos. Assim, metodologias de regionalização de vazões, que visam suprir a ausência de medições de vazões, a partir da utilização das informações hidrológicas de bacias com características físicas similares, são de vital importância. O Estado de São Paulo utiliza um método de regionalização de vazões formulado com dados das décadas de 1940 a 1980 para gestão de outorgas de água em regiões sem dados históricos fluviométricos. O presente trabalho avaliou este método de regionalização de vazões com valores mensais médios em cinco microbacias da Unidade de Gerenciamento de Recursos Hídricos do "Médio Paranapanema" (UGRHI 17), que compõem o Comitê de Bacia Hidrográfica do "Médio Paranapanema" (CBH-MP), analisando a aderência de suas curvas de permanência. O principal objetivo foi analisar se (1) as curvas de permanência que utilizam dados de regionalização de vazões proveem informação suficiente para a tomada de decisão e (2) quais impactos o uso da metodologia atual pode gerar. As análises foram feitas com três recortes temporais, usando dados observados anteriores e após 1990, bem como a série histórica completa. Dessa forma, evidências do impacto da desatualização do modelo de regionalização de vazões podem ser extraídas. O modelo de regionalização de vazões médias mensais utilizado pelo Estado de São Paulo apresentou subestimação de vazões, comprovada com a realização de testes de aderência estatística, com resultados piores em microbacias menores. As curvas de permanência obtidas a partir de dados de regionalização de vazões apresentaram melhor aderência aos valores observados anteriores a 1990. A principal fonte de incerteza na manutenção do uso dessa metodologia é sua desatualização frente a cenários de mudanças climáticas. O processo de outorga de água, quando baseado nesse método, apoia-se em cenários mais restritivos que os reais, enquanto para o planejamento de obras civis há baixa previsibilidade de eventos extremos, como enchentes. Com isso podem ser gerados impactos na segurança hídrica (com outorgas mais restritivas e menor previsibilidade de cheias) e empecilhos à sustentabilidade no uso da água nessas microbacias. Avanços nos estudos em regionalização de vazões, bem como a expansão das redes hidrométricas, ampliam a base de dados para tomada de decisão em gerenciamento de recursos hídricos nos comitês de bacias.
\end{abstract}

Palavras-chave: Série histórica; Disponibilidade hídrica; Curva de permanência; Hidrologia; Modelagem.

\section{ABSTRACT}

REVISITING FLOW REGIONALIZATION IN THE MIDDLE PARANAPANEMA REGION IN THE STATE OF SÃO PAULO: THE USE OF FLOW DURATION CURVES IN WATERSHEDS. The scarcity of information to support decision-making in water resources management is one of the main restrictions to the adequate use of such resources. Flow regionalization, which aims to overcome the lack of measured flow 
rate data by using hydrological information from other watersheds with similar physical characteristics, has vital importance. The State of São Paulo uses a flow regionalization method that was formulated with data from the 1940s to the 1980s in order to manage water use concession proposals in regions with no historical fluviometric data. The present study assessed the efficiency of this flow regionalization method by checking it against monthly mean flow rate values obtained for five watersheds of the "Middle Paranapanema" Water Resources Management Unit (UGRHI 17), which in turn composes the "Middle Paranapanema" Basin Committee (CBH-MP). The goodness of fit of the flow duration curves derived from flow regionalization data was analyzed, considering: (1) whether this kind of flow duration curves provide enough information for decision making, and (2) what impacts can be generated by the use of such flow regionalization method. The analyses were made for three time frames, using data obtained before and after 1990, and using the complete historical series. This procedure enabled to depict the shortcomings of the flow regionalization model built with outdated data. The underestimation of data was proven by goodness-of-fit tests that yielded the worst results for the smaller watersheds. On the other hand, the flow duration curves yielded better goodness of fit for mean flow rate values obtained before 1990. The main source of uncertainty in maintaining the use of this methodology is its outdated in face of climate change scenarios. When it comes to water use concessions, more restrictive scenarios than the real ones result the use of such flow regionalization model; when it comes to the planning of civil engineering works, the predictability of extreme events, such as floods, is underrated. The methodology can generate impacts on water security (with more restrictive concessions and underrated predictability of floods) and obstacles to sustainability of water use in the watersheds. Advances in the study of flow regionalization, as well as the expansion of hydrometric networks, can broaden the bases for decision making in water resource management in Basin Committees.

Keywords: Historical series; Water availability; Flow duration curve; Hydrology; Modeling.

\section{INTRODUÇÃO}

Estudos hidrológicos têm importância fundamental no planejamento e gerenciamento dos recursos hídricos em nível de microbacia hidrográfica, sendo a distribuição temporal das vazões mínimas ou de estiagem de grande importância em projetos de abastecimento de água, energia elétrica, irrigação, manutenção da qualidade da água, dentre outros.

Aliado a isso, a crescente demanda de água e o aumento dos níveis de poluição hídrica tornam as fontes disponíveis cada vez mais escassas, sendo necessária a otimização de seu uso para garantir segurança hídrica em seus fins de usos múltiplos e evitar grandes concentrações de poluentes em épocas de estiagem. Nesse contexto, a outorga do direito de uso da água, instrumento da Lei Federal $n^{\circ} 9.433$ de 1997, que institui a Política Nacional de Recursos Hídricos, tem como objetivos assegurar o controle quantitativo e qualitativo dos usos da água e o efetivo exercício dos direitos de acesso (BRASIL 1997).

Para o gerenciamento de recursos hídricos é necessária uma série de informações hidrológicas, porém, há um número reduzido de postos pluviométricos e fluviométricos para coleta desses dados hidrológicos no Brasil. Assim, de acordo com LOPES et al. (2016), o emprego de modelos é essencial para a estimativa dos valores de vazões de microbacias hidrográficas sem monitoramento.

A regionalização de vazões visa suprir a ausência de dados hidrológicos a partir da utilização das informações hidrológicas de outra bacia com características físicas similares. A regionalização de uma função ou variável pode ser estabelecida por meio da relação empírica entre valores da função e características conhecidas, espacialmente, do sistema hidrológico, ou em função de relações adimensionais (TUCCI 2001). Um dos métodos mais difundidos para a regionalização de vazões é o método tradicional, descrito pela ELETROBRÁS 
(1985), que consiste na identificação de regiões hidrologicamente homogêneas e no ajuste de equações de regressão entre as diferentes variáveis a serem regionalizadas, bem como as características físicas e climáticas das bacias de drenagem para cada região homogênea.

O Estado de São Paulo, por meio da Lei 9.034/94 (SÃO PAULO 1994), estabelece que a vazão de referência para orientar a outorga de direitos de uso de recursos hídricos é calculada com base na média mínima de 7 dias consecutivos e 10 anos de período de retorno $\left(\mathrm{Q}_{7,10}\right)$, estabelecendo como limite superior ao uso total outorgado a metade desse valor de referência, ou seja, a soma das vazões captadas em uma determinada microbacia hidrográfica não deve exceder $50 \%$ da respectiva vazão de referência $\left(\mathrm{Q}_{7,10}\right)$, quando a utilização de água nessa microbacia passa a ser considerada crítica e entrará em um regime de gerenciamento especial.

LIAZI et al. (1988) desenvolveram um estudo de regionalização de vazões média de longo período e mínima (de $n$ meses consecutivos e mínimas anuais de sete dias consecutivos), volumes de regularização interanual e curvas de permanência. Esse estudo, realizado pelo Departamento de Águas e Energia Elétrica (DAEE), baseou-se em dados dos totais anuais precipitados em 444 postos pluviométricos, nas séries de descargas mensais observadas em 219 estações fluviométricas e nas séries históricas de vazões diárias de 88 postos fluviométricos do Estado de São Paulo. Desde então, esse estudo tem sido utilizado pelo DAEE para estimar a disponibilidade hídrica de bacias hidrográficas do estado, sendo seu modelo implementado e disponibilizado no Sistema de Gerenciamento de Recursos Hídricos - SIGRH, disponível atualmente em formato de software em DAEE (2020).

WOLFF et al. (2014) consideram que a metodologia utilizada pelo DAEE apresenta, como limitações, coeficientes generalizados para extensas áreas e uso de dados da década de 40 a 80, tornando as estimativas destoantes do atual cenário de mudanças climáticas. Segundo OLIVEIRA \& FIOREZE (2011), com o aumento da frequência de eventos extremos, a quantificação e predição de vazões é primordial na resolução e prevenção de conflitos de demandas e ofertas de água doce em distintas escalas regionais, tornando a regionalização de vazões um aparato de extrema necessidade, assim como de grande importância na sua capacidade de previsibilidade frente aos atuais cenários de mudanças climáticas (ELESBON et al. 2015, PEREIRA \& CALDEIRA 2018).

A curva de permanência é uma ferramenta poderosa para visualizar a probabilidade de ocorrência de eventos hidrológicos extremos. Essa curva representa a relação entre a magnitude e a frequência das vazões diárias, semanais, mensais ou anuais de uma determinada área de drenagem (VOGEL \& FENNESSEY 1995, VIOLA et al. 2011, ZHANG et al. 2015). Uma curva de permanência possui uma ampla variedade de usos na gestão de recursos hídricos, entre os quais podem ser citados estudos de disponibilidade hídrica para abastecimento público, irrigação, navegação, análise da qualidade da água, estudos hidrelétricos, análise de frequência de fluxos ecológicos, entre outros (BLANCO et al. 2013, CASTELLARIN et al. 2007).

Assim, conhecer as vazões de permanência de um curso d'água é de relevante importância para o planejamento e a gestão dos recursos hídricos, por exemplo: a) para empreendimentos hidrelétricos, utiliza-se a vazão com $90 \%$ de frequência acumulada $\left(\mathrm{Q}_{90}\right)$ para analisar a energia firme da futura usina nesse local; b) para abastecimento público, utiliza-se a vazão com $95 \%$ de frequência acumulada $\left(Q_{95}\right)$ para o planejamento.

Deve-se levar em conta que a vazão, como todas as outras variáveis utilizadas para a caracterização de processos hidrológicos, possui comportamento aleatório, exigindo, para sua adequada avaliação, séries históricas - obtidas nos postos fluviométricos instalados em microbacias hidrográficas - representativas e confiáveis. Infelizmente, na maioria dos casos os dados hidrológicos são reduzidos ou inexistentes, devido aos elevados custos de implantação, operação e manutenção da rede hidrométrica. E justamente visando suprir as deficiências das redes hidrométricas, é possível construir curvas de permanência a partir dos dados modelados por regionalização de vazões. A aplicação de dados de regionalização de vazões em curvas de permanência já foi aplicada em diferentes lugares do mundo (MIMIKOU \& KAEMAKI 1985, YU et al. 2002, MAMUN et al. 2010, COSTA et al. 2012, WASEEM et al. 2015, MÜLLER \& THOMPSON 2016, BOSCARELLO et al. 2016, SWAIN \& PATRA 2017).

WOLFF et al. (2014) agruparam em duas categorias as metodologias mais comuns na literatura científica de regionalização de vazões, a saber: a) baseadas em equações de regressão aplicadas a regiões hidrologicamente homogêneas e; b) baseadas em técnicas de interpolação e extrapolação 
automáticas em ambiente de sistemas de informações geográficas (SIG). O método de regionalização de vazões de LIAZI et al. (1988) se enquadra na primeira categoria, utilizando dados observados entre 1940 e 1980 para predizer a variação regional da eficiência da transformação da relação quadrática entre chuva, evaporação, infiltração (percolação e transmissividade) e vazão. Vale ressaltar que os dados de entrada para a obtenção de vazões regionalizadas são a latitude e área $\left(\mathrm{em} \mathrm{km}^{2}\right)$ da microbacia.

O presente trabalho avaliou o método de regionalização de vazões médias de LIAZI et al. (1988), atualmente utilizado pelo DAEE no Estado de São Paulo, em cinco microbacias da Unidade de Gerenciamento de Recursos Hídricos do Médio Paranapanema (UGRHI-17), analisando a aderência das curvas de permanência geradas a partir de dados de regionalização de vazões com aquelas obtidas de dados de postos fluviométricos. O principal objetivo foi analisar se (1) as curvas de permanência que utilizam dados de regionalização de vazões proveem suficiente informação para a tomada de decisão e (2) quais impactos o uso da metodologia atual pode gerar.

\section{MATERIAIS E MÉTODOS}

\section{1 Área de estudo e séries históricas de dados}

A Unidade de Gerenciamento de Recursos Hídricos Integrada (UGRHI) Médio Paranapanema, $17^{\mathrm{a}}$ unidade da atual divisão hidrográfica de Estado de São Paulo, foi definida por critérios físicos, políticos, econômicos e sociais e está subordinada ao Comitê da Bacia Hidrográfica do Médio Paranapanema - CBH-MP, criado em 2 de Dezembro de 1994, em conformidade com a Lei Estadual $n^{\circ}$. 7.663/91. A Política Nacional Estadual de Recursos Hídricos criou os Comitês de Bacias Hidrográficas (CBHs), que são importantes espaços democráticos, de poder deliberativo e consultivo, composto por diferentes atores para gerenciar o uso dos recursos hídricos de forma integrada e descentralizada com a participação da sociedade (CARDOSO 2003). Participam dos CBHs representantes da União, do Estado e dos Municípios, Usuários de Água (qualquer pessoa física ou jurídica que utiliza a água) e pessoas ligadas às associações, organizações técnicas e de ensino, não-governamentais, entre outras sem fins lucrativos, reconhecidas pelo Conselho Estadual de Recursos
Hídricos (CERHI), com interesse na conservação e na recuperação da bacia hidrográfica.

A UGRHI Médio Paranapanema é composta por 42 municípios com sede nessa UGRHI, dentre eles, Assis, Itatinga, Ourinhos, Pardinho e Pratânia, e parcialmente por 13 municípios com sede em outra UGRHI, dentre eles, Botucatu, Lençóis Paulista e Marília. Abrange uma área de $16.749 \mathrm{~km}^{2} \mathrm{e}$ tem como principais corpos hídricos os rios Pardo, Turvo, Capivara, Novo e Pari. A UGRHI 17 está às margens da porção média do Rio Paranapanema. O Médio Paranapanema, segundo a classificação climática de Köppen-Geiger, é composto por municípios enquadrados como Cwa, Am e Cfa (ROLIM et al. 2007) e a temperatura média anual situa-se em torno de $20,6{ }^{\circ} \mathrm{C}$ (PRADO et al. 2003).

O Médio Paranapanema é uma região agrícola, onde durante o período de inverno são cultivadas espécies adaptadas a condições mais amenas de temperatura. Entre as espécies anuais cultivadas na região, pode-se citar trigo, aveia e o milho safrinha, além de espécies perenes, como café e seringueira, e semiperenes, como cana-de-açúcar e banana (PRELA-PANTANO et al. 2009).

As séries históricas de dados fluviométricos mensais médios apresentadas na tabela 1 foram obtidas do Banco de Dados Hidrológicos do DAEE (2018) e a localização das microbacias está ilustrada na figura 1. A escolha dos postos fluviométricos baseou-se nas microbacias com maiores períodos de monitoramento e com diferentes áreas de drenagem. Todas as séries históricas têm mais de 30 anos e se iniciam antes da formulação da metodologia de LIAZI et al. (1988). Considerou-se limite de falhas (meses sem dados) de $10 \%$ para cada ano hidrológico e independente de um período comum de dados.

A figura 2 apresenta o uso da terra nas bacias em 2017 (MAPBIOMAS 2019). Por meio dos mapeamentos anuais (1985-2017, MAPBIOMAS 2019) a dinâmica de uso da terra nas microbacias foi quantificada para avaliar a alterações ocorridas dentro do período estudado.

2.2 Curva de permanência geradas com dados fluviométricos e por regionalização de vazões

A curva de permanência de vazões demonstra a relação entre a vazão observada e as percentagens com que esta vazão é superada ou igualada durante um período de observação. Para sua construção é necessária a análise de frequência de vazões de cada série histórica, que consistiu em avaliar as séries de dados observados e obter a frequên- 
TABELA 1 - Séries históricas de dados de vazões médias mensais de postos fluviométricos na Unidade de Gerenciamento de Recursos Hídricos 17 - Médio Paranapanema.

\begin{tabular}{|c|c|c|c|c|c|}
\hline Posto & Município & Latitude & Longitude & $\begin{array}{c}\text { Área de } \\
\text { Drenagem }\left(\mathrm{km}^{2}\right)\end{array}$ & Periodo \\
\hline $6 \mathrm{D}-002$ & Águas de Santa Bárbara & $22^{\circ} 52^{\prime} 43^{\prime \prime} \mathrm{S}$ & $49^{\circ} 14^{\prime} 17^{\prime \prime} \mathrm{W}$ & $3.407,00$ & $1956-2017$ \\
\hline 6D-010 & São Pedro do Turvo & $22^{\circ} 45^{\prime} 05^{\prime \prime} \mathrm{S}$ & $49^{\circ} 44^{\prime} 06^{\prime \prime} \mathrm{W}$ & 720,00 & $1981-2017$ \\
\hline 7D-006 & Palmital & $22^{\circ} 48^{\prime} 59 " \mathrm{~S}$ & $50^{\circ} 18^{\prime} 57^{\prime \prime} \mathrm{W}$ & 934,00 & $1970-2017$ \\
\hline 7D-012 & Rancharia & $22^{\circ} 31^{\prime} 54^{\prime \prime} \mathrm{S}$ & $50^{\circ} 54^{\prime} 28^{\prime \prime} \mathrm{W}$ & 646,00 & $1979-2017$ \\
\hline 7D-013 & Maracaí & $22^{\circ} 37^{\prime} 14^{\prime \prime} \mathrm{S}$ & $50^{\circ} 41^{\prime} 04^{\prime \prime} \mathrm{W}$ & $1.560,00$ & $1979-2017$ \\
\hline
\end{tabular}
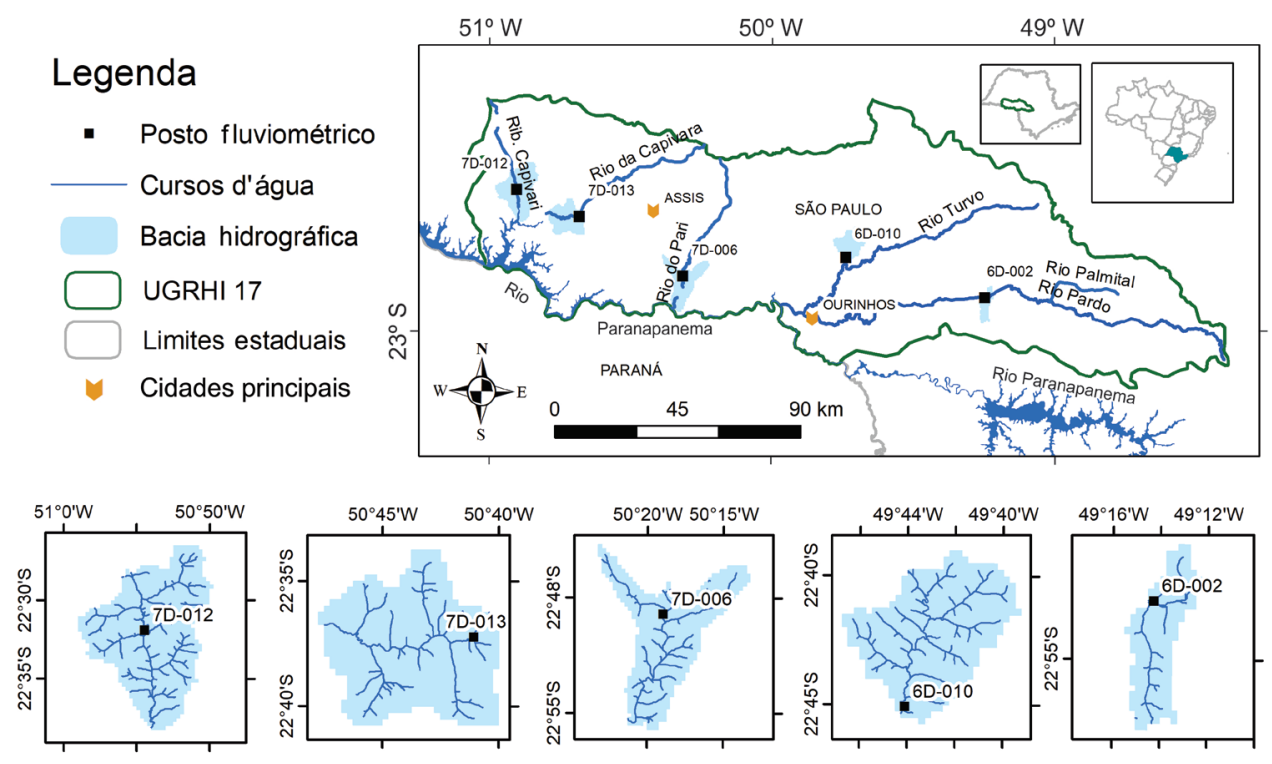

FIGURA 1 - Localização da UGRHI 17, Médio Paranapanema e microbacias hidrográficas monitoradas utilizadas para avaliação da regionalização de vazões utilizada pelo DAEE. Fonte (hidrografia): Base Cartográfica Integrada Digital do Brasil ao Milionésimo (IBGE 2009).
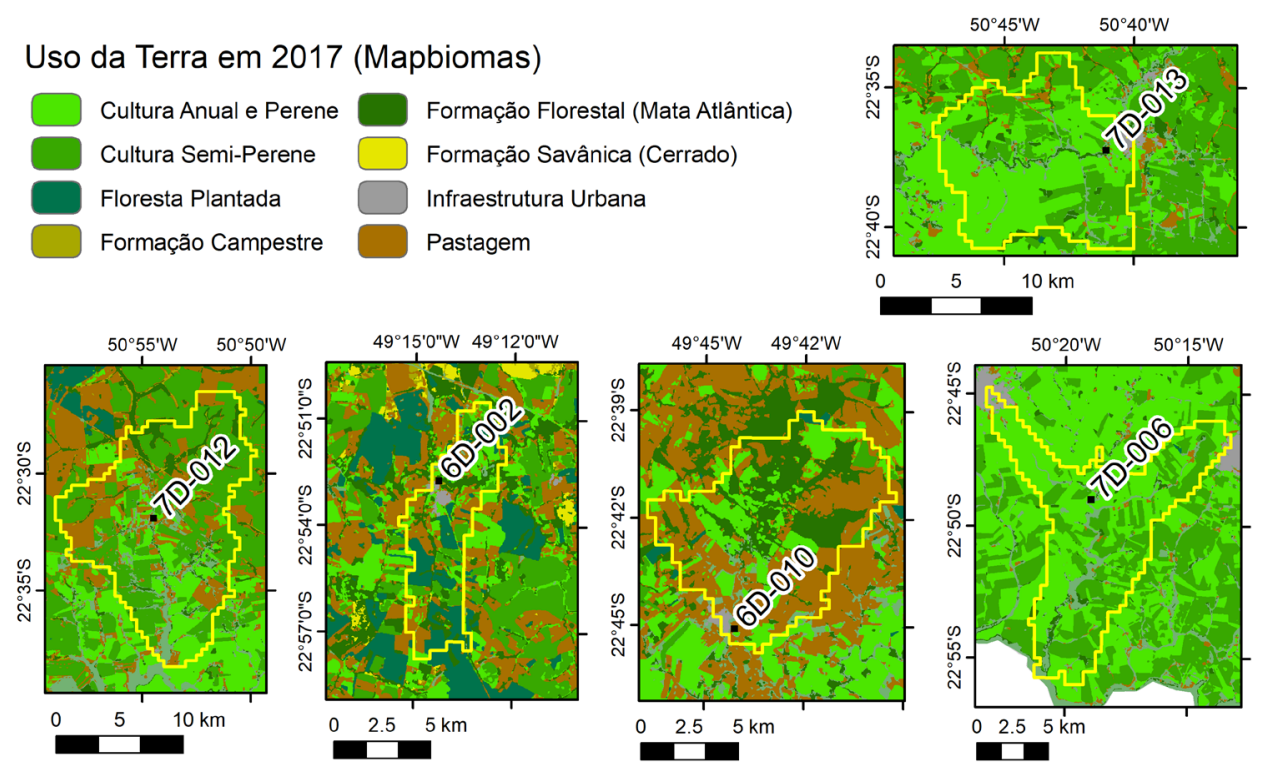

FIGURA 2 - Uso da terra nas microbacias em 2017, de acordo com MAPBIOMAS (2019). 
cia de ocorrência de um determinado valor, maior ou menor que um dado nível de vazão, como por exemplo, a vazão mínima que se comporta como um valor extremo. Essa frequência de ocorrência pode ser determinada pela distribuição de probabilidade dos dados observados, que representa a população da qual a amostra foi retirada. A avaliação dessa distribuição é uma forma de verificar a adequabilidade do modelo de regionalização de vazões frente à toda série histórica.

A partir do número de dados (n) e a amplitude dos dados (A) foram identificados o número de classes $(\mathrm{N})$ e o intervalo de classe $(\mathrm{k})$ pelas equações $1 \mathrm{e}$ 2 , respectivamente.

$$
\mathrm{N}=\sqrt{\mathrm{n}}
$$

Onde n é o número de dados de vazão mensal de cada posto fluviométrico e $\mathrm{N}$ é o número de classes a ser utilizada na análise de frequência desse posto.

$$
\mathrm{k}=\frac{\mathrm{A}}{\mathrm{N}}
$$

Onde $\mathrm{k}$ é o intervalo dos valores de vazão mensal utilizado em cada análise de frequência e A é a amplitude dos valores de vazão mensal do posto fluviométrico.

Construiu-se uma tabela com a amplitude e valores-limite de cada classe e suas respectivas frequências absolutas, relativas e acumuladas (a partir das relativas). Para cada curva de permanência obtida, tanto de vazões observadas quanto das modeladas por regionalização de vazões, foi gerado um gráfico com a frequência acumulada no eixo $x$ e com os limites inferiores de cada classe de vazão da análise de frequência no eixo $y$.

De posse dos valores da área de drenagem e das coordenadas geográficas das estações fluviométricas do DAEE, as vazões foram estimadas por intermédio da metodologia de LIAZI et al. (1988), disponível como aplicativo computacional na aba "Regionalização Hidrológica" em DAEE (2020).

Encontra-se em anexo ao presente artigo (Anexo 1) a planilha eletrônica (em formato Microsoft Excel) contendo a memória de cálculo (fórmulas abertas e editáveis) da construção das curvas de permanência das microbacias com dados fluviométricos observados e com dados de regionalização de vazões. Dessa forma, os resultados apresentados podem ser reproduzidos, assim como esta planilha pode ser utilizada com dados de outras áreas.

A análise estatística da probabilidade de ocorrência de vazões é útil para planejamento de obras civis e de abastecimento elétrico ou de água. De acordo com ELETROBRÁS (2000), para as microcentrais hidrelétricas a vazão de projeto para sistemas isolados (vazão de turbina) é com 95\% de permanência, enquanto para sistemas interligados à rede de energia adota-se a vazão a $50 \%$ de permanência. As vazões de maior probabilidade são menores (pois são atendidas durante a maior parte do tempo), enquanto vazões de baixa probabilidade são maiores, caracterizando enchentes, por isso são úteis para projetos de pontes e canalizações de rios.

No presente trabalho foram feitas quatro curvas de permanência para cada posto fluviométrico: 1) com toda a série histórica de vazões médias mensais de acordo com a tabela 1;2) utilizando apenas os dados anteriores a 1990; 3) utilizando apenas os dados posteriores a 1990 e 4) utilizando dados de regionalização de vazões.

Para quantificar o erro da regionalização de vazões foi adotada a raiz do erro quadrático médio (RMSE - Root Mean Square Error), seguindo a equação 3.

$$
\text { RMSE }=\sqrt{\sum_{i=1}^{n} \frac{\left(o_{i}-h_{t}^{*}\right)^{2}}{n}}
$$

Onde $h_{t}^{*}$ são os valores estimados pelo modelo de LIAZI et al. (1988), $o_{i}$ são os valores observados e $n$ é o número de observações. O valor RMSE é usado para conhecer o grau de tendência na previsão e é sensível a erros altos. O RMSE deve ser tão próximo de zero quão melhor seja a estimativa.

\subsection{Testes de aderência}

Para avaliar a aderência estatística entre as curvas de permanência geradas a partir de dados observados e por dados de regionalização de vazões foram utilizados os testes do coeficiente de determinação $\left(\mathrm{R}^{2}\right)$, coeficiente de massa residual (CRM), de Kolmogorov-Smirnov e de índice de concordância de Wilmott.

$\mathrm{O}$ coeficiente de determinação $\left(\mathrm{R}^{2}\right)$ descreveu a qualidade do ajuste obtido entre a curva simulada $\mathrm{e}$ os dados medidos, podendo variar de zero (quando o modelo não explica os dados medidos) a 1 (quando os dados explicam totalmente os dados medidos), dentro de determinado nível de significância, por meio da equação 4.

$$
R^{2}=1-\sum_{i=1}^{n} \frac{\left(o_{i}-e_{i}\right)^{2}}{\left(o_{i}-\bar{o}\right)^{2}}
$$

Onde $e_{i}$ são os valores estimados pelo modelo de LIAZI et al. (1988), o $o_{i}$ são os valores 
observados, $\bar{o}$ é a média das observações e $n$ é o número de valores observados.

O coeficiente de massa residual avaliou a aderência estatística por meio da equação 5 , sendo interpretado como um indicador de superestimação quando seu valor for positivo (CRM $>0$ ), uma vez que os termos dos valores estimados no denominador são positivos, e de subestimação quando for negativo $(\mathrm{CRM}<0)$, quando os termos dos valores observados no denominador são negativos, sendo a condição de aderência ótima o valor nulo (CRM $=0)$.

$$
C R M=\sum_{i=1}^{n} \frac{e_{i}-o_{i}}{o_{i}}
$$

Onde $e_{i}$ são os valores estimados e $o_{i}$ são os valores observados.

$\mathrm{O}$ teste de Kolmogorov-Smirnov (LILLIEFORS 1967) determinou se a distribuição de probabilidade estimada difere da probabilidade observada. Avaliou-se a partir de um valor estabelecido através da equação 6 que, se maior que o crítico, indica a rejeição da hipótese de normalidade dos dados com determinado nível de significância.

$$
K S=\sup |E(x)-O(x)|
$$

Onde $K S$ é a diferença máxima entre os valores da distribuição de probabilidade estimada e a observada, com valor $\mathrm{p}>0,10, E(x)$ é a frequência da distribuição estimada e $o(x)$ é a distribuição observada. O teste de aderência de KolmogorovSmirnov pressupõe amostras independentes; assim, para garantir a independência foi realizada uma amostragem randômica de 15 valores.

O índice de concordância de Wilmott quantifica a precisão dos valores estimados em relação aos medidos em um valor que varia de 0 a 1 , sendo tanto mais preciso quanto mais próximo seja de 1 . Sua formulação matemática é apresentada na equação 7.

$$
W=100\left[1-\frac{\sum\left(e_{i}-o_{i}\right)^{2}}{\sum\left(\left|e_{i}-m\right|+\left|o_{i}-m\right|\right)^{2}}\right]
$$

Onde $W$ é o índice de concordância de Wilmott, $e_{i}$ é o valor de vazão estimada pelo modelo de regionalização de vazões, $o_{i}$ é a vazão medida e $m$ é a vazão observada média.

A análise de aderência tem como objetivo embasar a avaliação da regionalização de vazões. CRUZ (2001) afirma que pequenas e médias bacias (menores que 900 e $4.000 \mathrm{~km}^{2}$, respectivamente) permitem que dados de monitoramento sejam utilizados para validação de regionalizações de vazões com suficiente representatividade.

\section{RESULTADOS E DISCUSSÃO}

A dinâmica do uso da terra tem impacto direto no comportamento hidrológico de microbacias, assim, analisá-la no período estudado fornece subsídios para compreender mudanças hidrológicas ao longo tempo. A respeito do uso da terra em 2017 nas microbacias estudadas, de acordo com dados de MAPBIOMAS (2019), destaca-se que na microbacia localizada em Águas de Santa Bárbara há a maior porcentagem de área urbanizada $(85 \%)$, enquanto as demais microbacias têm porcentagem menor que 50\%. Além da área urbanizada, a microbacia em Águas de Santa Bárbara apresenta grande porcentagem de pastagem $(20 \%)$. As demais microbacias, em geral, têm predominância de agropecuária (mosaico de agricultura anual com pastagem). As microbacias de Palmital e Maracaí têm predominância de agricultura anual e perene (70 e 61\%, respectivamente), enquanto São Pedro do Turvo e Rancharia têm predominância de pastagem (71 e 68\%, respectivamente). Com relação à dinâmica do uso da terra entre 1985 e 2017, destaca-se que houve conversão de $15 \%$ da área de pastagem em floresta (regeneração) e aumento de $20 \%$ na área de cultivos anuais na microbacia em Águas de Santa Bárbara; entretanto houve aumento de $40 \%$ na área urbanizada sobre áreas florestais $(4 \%)$ e agrícolas $(36 \%)$, indicando aumento na área impermeabilizada. Na microbacia de Palmital o avanço da área urbana ocorreu exclusivamente sobre florestas nesse período, apresentando taxa de conversão de floresta em área urbana de 5\%. Em Rancharia e Maracaí a principal conversão foi a de pastagem em culturas anuais $(45 \%$ e $59 \%$, respectivamente). A microbacia em São Pedro do Turvo apresentou relativa estabilidade no uso da terra.

A análise descritiva das séries históricas, exposta nos boxplots da figura 3, mostra que as maiores microbacias, localizadas em Águas de Santa Bárbara e Maracaí, apresentaram os maiores valores medianos de vazões, limites inferior e superior da série e maiores valores extremos (expressos nos outliers).

A microbacia localizada em Águas de Santa Bárbara apresentou vazão média de $37,8 \mathrm{~m}^{3} / \mathrm{s}$, chegando a atingir uma vazão extrema de $166,3 \mathrm{~m}^{3} / \mathrm{s}$, sendo a maior vazão dentre as cinco séries históricas. Todos os registros de vazão média mensal maiores que $100 \mathrm{~m}^{3} / \mathrm{s}$ ocorreram após 1990 . As 

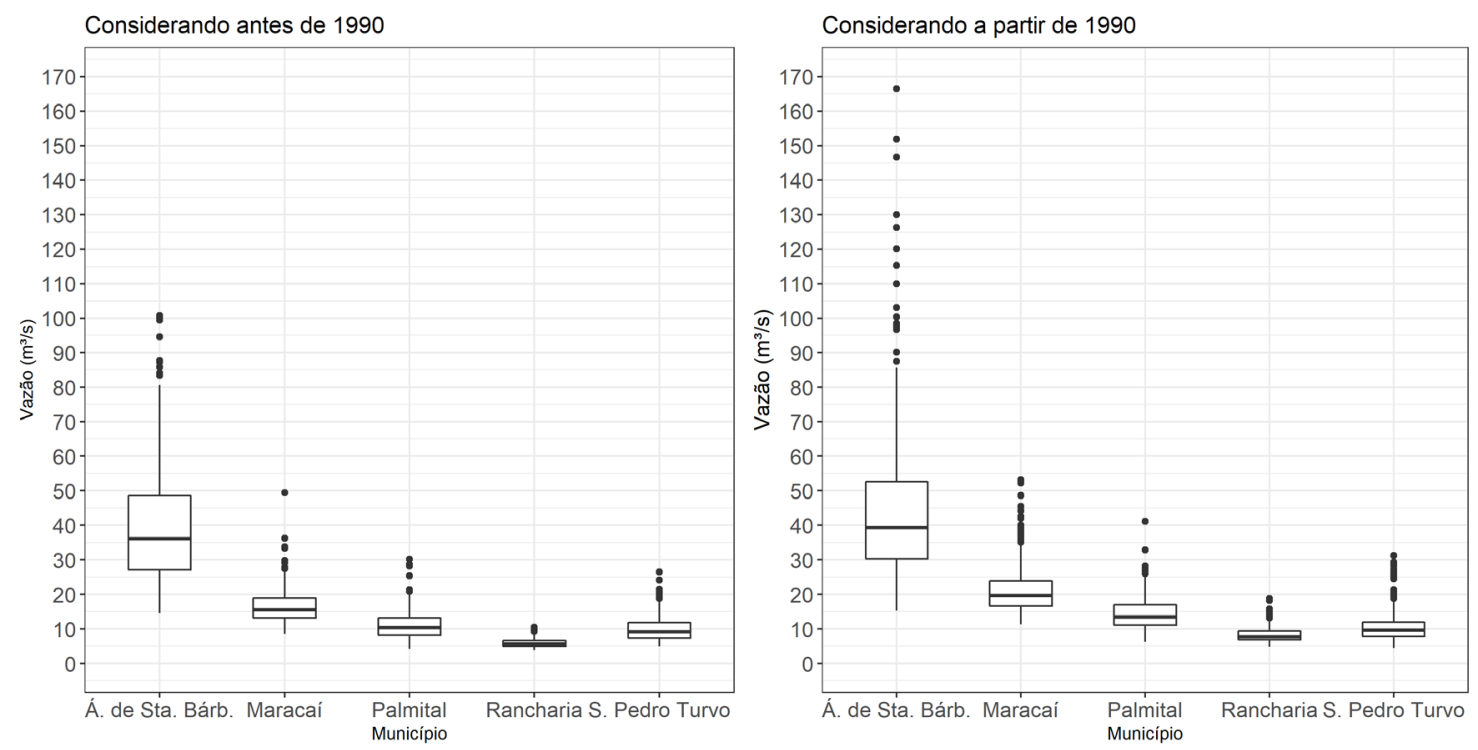

FIGURA 3 - Boxplot das séries históricas de dados de vazões médias mensais de postos fluviométricos na UGRHI 17 - Médio Paranapanema, de acordo com o município e considerando dois recortes temporais (antes e após 1990).

demais microbacias, majoritariamente ocupadas com atividade rural, apresentam menores vazões médias em suas séries históricas, a saber, Maracaí $\left(19,3 \mathrm{~m}^{3} / \mathrm{s}\right)$, Palmital $\left(14,6 \mathrm{~m}^{3} / \mathrm{s}\right)$, São Pedro do Turvo $\left(9,3 \mathrm{~m}^{3} / \mathrm{s}\right)$ e Rancharia $\left(7,2 \mathrm{~m}^{3} / \mathrm{s}\right)$.

As figuras 4 e 5 apresentam as curvas de permanência com vazões médias observadas e com vazões obtidas por meio do método de regionalização de vazões (LIAZI et al. 1988). Em cada cur-
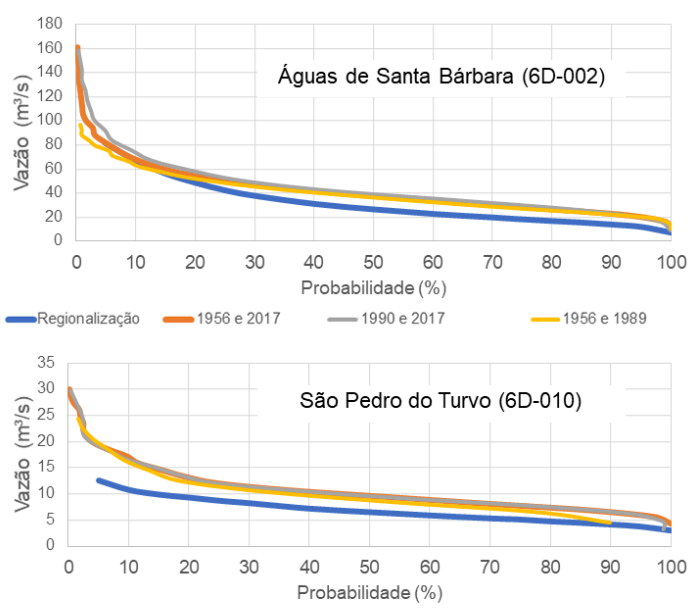

—Regionalização — 1981 e $2017 \quad$ — 1990 e $2017 \quad 1981$ e 1989

FIGURA 4 - Curvas de permanência com vazões médias observadas (em três recortes temporais) e com vazões obtidas por meio do método LIAZI et al. (1988) de regionalização de vazões nas microbacias de Águas de Santa Bárbara e São Pedro do Turvo/SP.
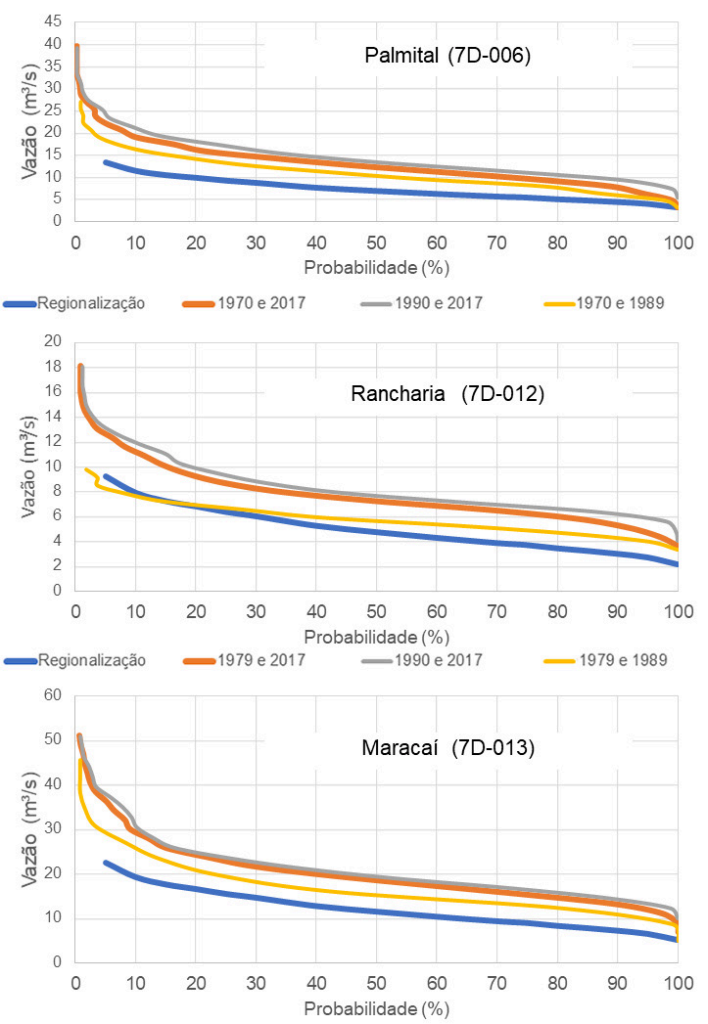

—Regionalização — 1979 e $2017 \quad-1990$ e $2017 \quad-1979$ e 1989

FIGURA 5 - Curvas de permanência com vazões médias observadas (em três recortes temporais) e com vazões obtidas por meio do método LIAZI et al. (1988) de regionalização de vazões nas microbacias de Palmital, Rancharia e Maracaí/SP. 
va de permanência são apresentadas quatro séries de dados. As cores das curvas foram padronizadas para facilitar a comparação dos recortes temporais (antes de 1990, após 1990 e considerando toda a série histórica disponível no posto fluviométrico) com a curva obtida com dados de regionalização de vazões. As curvas de permanência das microbacias de Águas de Santa Bárbara e São Pedro do Turvo apresentam comportamentos notavelmente distintos (Figura 3). As demais microbacias apresentaram comportamentos semelhantes entre si (Figura 4).

A tabela 2 apresenta os valores obtidos com a realização de testes de aderência estatística para a verificação de adequabilidade do método LIAZI et al. (1988) com os dados de vazões médias das cinco microbacias da UGRHI 17 estudadas. Para cada posto fluviométrico e microbacia foram analisados três recortes temporais: 1) toda a série histórica de vazões médias mensais de acordo com a tabela 1 ; 2) apenas os dados anteriores a 1990 e 3) utilizando apenas os dados a partir de 1990. Dessa forma, evidências do impacto da desatualização do modelo de regionalização de vazões podem ser extraídos.

Em todas as simulações houve subestimação. No recorte temporal que utiliza as séries históricas completas, Águas de Santa Bárbara apresentou subestimativa de $22,6 \%\left(6,32 \mathrm{~m}^{3} / \mathrm{s}\right.$, com RMSE de $\left.6,90 \mathrm{~m}^{3} / \mathrm{s}\right)$, São Pedro do Turvo, 33,81\% (3,37 $\mathrm{m}^{3} / \mathrm{s}$, com RMSE de 3,58 m³/s), Palmital, 39,31\% $\left(4,50 \mathrm{~m}^{3} / \mathrm{s}\right.$, com RMSE de $\left.4,68 \mathrm{~m}^{3} / \mathrm{s}\right)$, Rancharia, $53,59 \%\left(2,31 \mathrm{~m}^{3} / \mathrm{s}\right.$, com RMSE de $\left.2,34 \mathrm{~m}^{3} / \mathrm{s}\right)$, e Maracaí, 34,88\% (6,39 m³/s, com RMSE de 6,82 $\left.\mathrm{m}^{3} / \mathrm{s}\right)$. OLIVEIRA \& FIOREZE (2011) indicam
$10 \%$ como limite de tolerância para subestimativas; excedendo-se esse valor, as simulações são consideradas inadequados para fins de outorga. Em termos gerais, a curva de permanência que utilizou regionalização de vazões apresentou maior aderência com as curvas de permanências baseadas em dados anteriores a 1990.

A figura 4 expõe dois comportamentos bastante particulares. Para a microbacia localizada em Águas de Santa Bárbara as curvas de permanência obtidas a partir da regionalização de vazões e com dados anteriores a 1990 adequaram-se bem em relação às maiores vazões, que nesse período foram mais baixas que as vazões extremas registradas a partir de 1990, das quais a regionalização de vazões não foi capaz de detectar. Já na microbacia de São Pedro do Turvo todas as curvas de permanência obtidas de dados observados se aderiram entre si, mas obtiveram baixa aderência à regionalização de vazões. A microbacia localizada em Rancharia (Figura 5) apresentou a maior subestimação entre todas as microbacias, sendo ela a de menor área de drenagem.

Os resultados do coeficiente de massa residual (CRM) indicam subestimação para a regionalização de vazões em todos os postos, situação que a análise visual dos gráficos da figura 3 já havia sugerido. Os valores de $\mathrm{R}^{2}$ indicam que as duas curvas mantêm a mesma tendência decrescente. $\mathrm{O}$ valor crítico encontrado para o teste KS foi de $\alpha=$ 0,34 , evidenciando que o método de regionalização de vazões não se adequou normalmente à nenhuma série histórica. O índice de concordância de

TABELA 2 - Testes de aderência entre a distribuição das vazões médias observadas e estimadas por meio do método LIAZI et al. (1988) de regionalização de vazões.

\begin{tabular}{ccccccc}
\hline & \multicolumn{5}{c}{ Teste de Aderência } & \multicolumn{2}{c}{ Raíz do Erro Médio } \\
& Recorte Temporal & $C R M$ & $R^{2}$ & $K S$ & $W$ & Quadrático $\left(\mathrm{m}^{3} / \mathrm{s}\right)$ \\
\hline \multirow{2}{*}{ Águas de } & $1956-2017$ & $-0,24$ & 0,89 & 0,42 & 0,45 & 6,90 \\
Santa Bárbara & $1956-1989$ & $-0,22$ & 0,92 & 0,41 & 0,51 & 1,26 \\
& $1990-2017$ & $-0,24$ & 0,87 & 0,42 & 0,32 & 9,85 \\
\hline \multirow{2}{*}{ São Pedro } & $1981-2017$ & $-0,69$ & 0,86 & 0,57 & 0,38 & 3,58 \\
do Turvo & $1981-1989$ & $-0,67$ & 0,85 & 0,56 & 0,48 & 3,21 \\
& $1990-2017$ & $-0,63$ & 0,86 & 0,58 & 0,56 & 3,42 \\
\hline \multirow{3}{*}{ Palmital } & $1970-2017$ & $-0,77$ & 0,81 & 0,54 & 0,45 & 4,68 \\
& $1970-1989$ & $-0,72$ & 0,86 & 0,54 & 0,48 & 3,99 \\
& $1990-2017$ & $-0,73$ & 0,80 & 0,53 & 0,41 & 4,21 \\
\hline \multirow{3}{*}{ Rancharia } & $1979-2017$ & $-0,55$ & 0,82 & 0,56 & 0,45 & 2,34 \\
& $1979-1989$ & $-0,54$ & 0,82 & 0,55 & 0,49 & 2,01 \\
& $1990-2017$ & $-0,55$ & 0,82 & 0,56 & 0,39 & 2,15 \\
\hline \multirow{2}{*}{ Maracaí } & $1979-2017$ & $-0,61$ & 0,81 & 0,50 & 0,37 & 6,82 \\
& $1979-1989$ & $-0,63$ & 0,80 & 0,50 & 0,34 & 5,98 \\
& $1990-2017$ & $-0,57$ & 0,82 & 0,49 & 0,39 & 6,45 \\
\hline
\end{tabular}


Wilmott apresentou valores considerados baixos, já que são iguais ou menores a 0,50 , indicando um modelo de baixa capacidade de predição.

A comparação das probabilidades de vazões a partir de dados simulados e observados denota a possibilidade de problemas de gestão, por exemplo, se durante a outorga, ao utilizar dados da regionalização com valores no período de estiagem maiores do que os valores reais, poderia ocorrer uma outorga de água maior que a capacidade real, causando escassez no futuro. A inclinação da curva de permanência indica que o escoamento de base (fluxo hídrico persistente) é pequeno, pois há grande diferença entre possibilidade de fortes cheias (nas probabilidades mais baixas) e de vazões mínimas muito baixas (nas probabilidades mais altas), aumentando a inclinação da curva. Esse comportamento evidencia uma potencial ineficiência da infiltração no solo e elevado potencial de escoamento superficial, que merecem ser estudadas em futuros trabalhos mais profundos sobre a relação entre variação das vazões e alterações na morfologia das bacias hidrográficas causados pela dinâmica do uso da terra.

PEREIRA \& CALDEIRA (2018) aplicaram os mesmos testes estatísticos na avaliação da modelagem das vazões mínimas da microbacia do Rio Negro, a partir da distribuição de Gumbel, e identificaram altos valores de $\mathrm{R}^{2}$ com baixos valores de KS e negativos de CRM, ou seja, um comportamento similar ao aqui identificado. ARAGÃO et al. (2013), estudando a intensidade de chuvas diárias, encontrou $\mathrm{R}^{2}$ constante de 0,99 em toda série histórica, a despeito das variações de erro durante o período estudado, mostrando a necessidade de analisar $\mathrm{R}^{2}$ conjuntamente com outros testes de aderência. Cabe ressaltar que outras avaliações de modelagem de curvas de permanência consideraram apenas o $\mathrm{R}^{2}$ e erro médio relativo, como NOVAES et al. (2007), SANTOS \& STEVAUX (2015) e BAZZO et al. (2017), sem a análise de outros fatores de aderência estatística em adição à linha de tendência, além de apresentarem algumas regressões com erro médio acima de $10 \%$, mesmo com $\mathrm{R}^{2}$ maior que $97 \%$, o que geraria insegurança para fins de outorga de água.

Observou-se piores resultados em microbacias menores, como já previsto por TUCCI (2001), uma vez que extrapolações para essas microbacias não consideram contribuições do aquífero. $\mathrm{O}$ principal fator de incerteza na manutenção do uso da metodologia de LIAZI et al. (1988) é estar desatualizada frente a cenários de mudanças climáti- cas (WOLFF et al. 2014), já que sua série histórica fundamental precede a década de 1990, prejudicando sua capacidade preditora e gerando impactos negativos ao cálculo da $\mathrm{Q}_{7,10}, \mathrm{Q}_{90}$ e $\mathrm{Q}_{95}$, principais índices aplicáveis à outorga de água pelo DAEE. Como a metodologia desenvolvida por LIAZI et al. (1988) trata de análises de regressão baseadas em dados medidos entre 1940 e 1980, pode não captar adequadamente comportamentos anômalos. Para tanto, ressalta-se que com maiores séries históricas disponíveis é possível a construção de métodos de regionalização de vazões mais robustos e com maior capacidade preditiva.

\section{CONSIDERAÇÕES FINAIS}

O modelo de regionalização de vazões médias de LIAZI et al. (1988) não se adequou aos dados observados de cinco microbacias da UGRHI 17 - Médio Paranapanema, apresentando subestimação de vazões em todos os recortes temporais, com maior impacto nas comparações com vazões mensais médias posteriores a 1990.

As curvas de permanência que utilizam dados de regionalização de vazões fornecem informação mais restritiva que a real para a tomada de decisão em outorga de água. Há baixa previsibilidade de eventos extremos, como enchentes, o que torna seu uso inadequado para o planejamento de obras civis, como pontes. Com isso podem ser gerados impactos na segurança hídrica (com outorgas mais restritivas e menor previsibilidade de cheias) e empecilhos à sustentabilidade no uso da água nessas microbacias.

A utilização de dados de regionalização de vazões pelo Comitê de Bacia é essencial para tomada de decisão em áreas com dados escassos ou sem monitoramento. Assim, avanços na pesquisa nesse tema, bem como a ampliação da rede hidrométrica, ampliam a base de dados para tomada de decisão no gerenciamento integrados dos recursos hídricos.

\section{AGRADECIMENTOS}

Os autores agradecem aos relatores e editores da Revista do Instituto Geológico pelas sugestões que enriqueceram o trabalho.

\section{REFERÊNCIAS BIBLIOGRÁFICAS}

ARAGÃO, R.; SANTANA, G.R.; COSTA, C.E.; CRUZ, M.A.; FIGUEIREDO, E.F.; 
SRINIVASAM, V. 2013. Chuvas intensas para o estado de Sergipe com base em dados desagregados de chuva diária. Revista Brasileira de Engenharia Agrícola e Ambiental, 17(3): 243-252. https://doi. org/10.1590/S1415-43662013000300001

BAZZO, K.R.; GUEDES, H.A.S.; CASTRO, A.S.; SIQUEIRA, T.M.; TEIXEIRA-GANDRA, C.F.A. 2017. Regionalização da vazão Q95: comparação de métodos para a bacia hidrográfica do Rio Taquari-Antas, RS. Revista Ambiente e Água, 12: 855-870. http:// doi.org/10.4136/ambi-agua.2032

BLANCO, C.J.C.; SANTOS, S.S.M.; QUINTAS, M.C.; VINAGRE, M.V.A.; MESQUITA, A.L.A. 2013. Contribution to hydrological modelling of small Amazonian catchments: application of rainfall-runoff models to simulate flow duration curves. Hydrological Sciences Journal, 58(7): 1423-1433. https:// doi.org/10.1080/02626667.2013.830727

BOSCARELLO,L.;RAVAZZANI,G.; CISLAGHI, A.; MANCINI, M. 2016. Regionalization of flow-duration curves through catchment classification with streamflow signatures and physiographic climate indices. Journal of Hydrological Engineering, 21(3): 05015027. https://doi.org/10.1061/(ASCE)HE.19435584.0001307

BRASIL. 1997. Lei $n^{\circ} 9.433$, de 8 de janeiro de 1997. Institui a Política Nacional de Recursos Hídricos, cria o Sistema Nacional de Gerenciamento de Recursos Hídricos, regulamenta o inciso XIX do art. 21 da Constituição Federal, e altera o $\operatorname{art.~}^{\circ}$ da Lei $\mathrm{n}^{\circ} 8.001$, de 13 de março de 1990, que modificou a Lei $\mathrm{n}^{\circ} 7.990$, de 28 de dezembro de 1989. Diário Oficial da União, Brasília, 09 jan. 1997.

CARDOSO, M.M.L. 2003. Desafios e potencialidades dos comitês de bacias hidrográficas. Ciência e Cultura, 55(4): 4041.

CASTELLARIN, A.; CAMORANI, G.; BRATH, A. 2007. Predicting annual and long-term flow duration curves in ungauged basins. Advances on Water Resources, 30: 937-953. https://doi. org/10.1016/j.advwatres.2006.08.006
COSTA, A.S.; CARIELLO, B.L.; BLANCO, C.J.C.; PESSOA， F.C.L. 2012. Regionalização de curvas de permanência de vazão de regiões hidrográficas do Estado do Pará. Revista Brasileira de Meteorologia, 27(4): 413-422. https://doi.org/10.1590/ S0102-77862012000400005

CRUZ, J.C. 2001. Disponibilidade hídrica para outorga: avaliação de aspectos técnicos $e$ conceituais. Instituto de Pesquisas Hidráulicas, UFRGS, Porto Alegre, Tese de Doutorado em Engenharia, 150 p.

DAEE - DEPARTAMENTO DE ÁGUAS E ENERGIA ELÉTRICA. 2018. Banco de Dados Hidrológicos. Disponível em http:// www.hidrologia.daee.sp.gov.br/. Acesso 20 mar. 2020.

DAEE - DEPARTAMENTO DE ÁGUAS E ENERGIA ELÉTRICA. 2020. Outorgas. Disponível em http://www.daee.sp.gov.br/ site/outorga/. Acesso 2 out. 2020.

ELESBON, A.A.A.; SILVA, D.D.; SEDIYAMA, G.C.; GUEDES, H.A.S.; RIBEIRO, C.A.A.; RIBEIRO, C.B. 2015. Multivariate statistical analysis to support the minimum streamflow regionalization. Engenharia Agrícola, 35(5): 838-851. http://doi.org/10.1590/1809-4430Eng.Agric.v35n5p838-851/2015

ELETROBRÁS. 1985. Metodologia para regionalização de vazões. Centrais Elétricas Brasileiras S.A., Rio de Janeiro, v. 1, 250 p.

ELETROBRÁS. 2000 Diretrizes para estudos e projetos de pequenas centrais hidrelétricas. Ministério das Minas e Energia, Rio de Janeiro, $150 \mathrm{p}$.

IBGE - INSTITUTO BRASILEIRO DE GEOGRAFIA E ESTATÍSTICA. 2009. Base Cartográfica Integrada do Brasil ao Milionésimo Digital. IBGE, Rio de Janeiro. Disponível em https://www. ibge.gov.br/geociencias/cartas-e-mapas/ folhas-topograficas/15808-folhas-da-cartainternacional-do-mundo-ao-milionesimo. html $?=\& \mathrm{t}=$ acesso-ao-produto/. Acessado em 25 jul. 2020.

LIAZI, A.; CONEJO, J.L.; PALOS, J.C.F.; CINTRA, P.S. 1988. Regionalização 
hidrológica no Estado de São Paulo. Revista Águas e Energia Elétrica-DAEE, 14: 4-10.

LILLIEFORS, H.W. 1967. On the KolmogorovSmirnov test for normality with mean and variance unknown. Journal of the American Statistical Association, 62(318): 399-402. https://doi.org/10.2307/2283970

LOPES, T.R.; PRADO, G.; ZOLIN, C.A.; ANTONIEL, L.S. 2016. Regionalização de vazões máximas e mínimas para a bacia do Rio Ivaí - PR. Irriga, 21(1): 188-201. https:// doi.org/10.15809/irriga.2016v21n1p188-201

MAMUN, A.A.; HASHIM, A.; DAOUD, J.I. 2010. Regionalisation of low flow frequency curves for the peninsular Malaysia. Journal of Hydrology, 381(1-2): 174-180. https://doi. org/10.1016/j.jhydrol.2009.11.039

MAPBIOMAS. 2019. Coleção 2.3. Disponível em http://mapbiomas.org/pages/database/ mapbiomas_collection. Acessado em 20 mar. 2020.

MIMIKOU, M.; KAEMAKI, S. 1985. Regionalization of flow duration characteristics. Journal of Hydrology, 82(12): 77-91. https://doi.org/10.1016/00221694(85)90048-4

MÜLLER, M.F.; THOMPSON， S.E. 2016. Comparing statistical and process-based flow duration curve models in ungauged basins and changing rain regimes. Hydrology and Earth System Sciences, 20(2): 669-683. https://doi.org/10.5194/hess-20-669-2016

NOVAES， L.F.; PRUSKI， F.F.; QUEIROZ, D.O.; RODRIGUEZ, R.D.G.; SILVA, D.D.; RAMOS, M.M. 2007. Avaliação do desempenho de cinco metodologias de regionalização de vazões. Revista Brasileira de Recursos Hidricos, 12: 85-93. https://doi. org/10.21168/rbrh.v12n2.p51-61

OLIVEIRA, L.F., FIOREZE, A.P. 2011. Estimativas de vazões mínimas mediante dados pluviométricos na Bacia Hidrográfica do Ribeirão Santa Bárbara, Goiás. Revista Brasileira de Engenharia Agrícola e Ambiental, 15(1): 9-15. https://doi. org/10.1590/S1415-43662011000100002
PEREIRA, G.S.; CALDEIRA, F.C. 2018. Avaliação da distribuição de Gumbel na determinação de vazões mínimas da subbacia do Rio Negro. Águas Subterrâneas, 32(1): 11-16. https://doi.org/10.14295/ras. v32i1.28926

PRADO, H.; MENK, J.R.F.; TREMOCOLDI, W.A.; JORGE, J.A. 2003. Levantamento pedológico detalhado do Pólo Regional de Desenvolvimento Tecnológico dos Agronegócios do Médio Paranapanema, Assis (SP). Campinas: Instituto Agronômico. 19 p. (Série Pesquisa APTA, Boletim Científico, 7).

PRELA-PANTANO, A.; ROLIM, G.S.; CAMARGO, M.B.P. 2009. Probabilidade de ocorrência de temperaturas mínimas menores que $5{ }^{\circ} \mathrm{C}$ na região do médio Paranapanema. Bragantia, 68(1): 279-284. https://doi. org/10.1590/S0006-87052009000100030

ROLIM, G.S.; CAMARGO, M.B.P.; LANIA, D.G.; MORAES, J.F.L. 2007. Classificação Climática de Köppen e de Thornthwaite e sua aplicabilidade na determinação de Zonas Agroclimáticas para o Estado de São Paulo. Bragantia, 66(4): 711-720. https://doi. org/10.1590/S0006-87052007000400022

SANTOS, V.C.; STEVAUX, J.C. 2015. Estimativa e regionalização hidrológica de vazões médias e produção de sólidos suspensos para a bacia hidrográfica do Rio Ivaí - Estado do Paraná. Geographia Meridionalis, 1(2): 384404. https://doi.org/10.15210/gm.v1i2.6879

SÃO PAULO. 1994. Lei $\mathrm{n}^{\circ}$ 9034, de 27 de dezembro de 1994. Dispõe sobre o Plano Estadual de Recursos Hídricos - PERH, a ser implantado no período 1994 e 1995, em conformidade com a Lei n. 7663, de 30 de dezembro de 1991, que instituiu normas de orientação à Política Estadual de Recursos Hídricos. Diário Oficial do Estado de São Paulo, São Paulo, 27 dez. 1994.

SWAIN, J. B.; PATRA, K. C. 2017. Streamflow Estimation in ungauged catchments using regional flow duration curve: comparative study. Journal of Hydrologic Engineering, 22(7): 04017010. https://doi.org/10.1061/ (ASCE)HE.1943-5584.0001509 
TUCCI, C.E.M. 2001. Regionalização de vazões. In: C.E..M. Tucci (Org.) Hidrologia: ciência e aplicação. Porto Alegre, ABRH/UFRGS, $2^{\text {a }}$ ed., p. 573-620.

VIOLA, F.; NOTO, L.V.; CANNAROZZO, M.; LA LOGGIA, G. 2011. Regional flow duration curves for ungauged sites in Sicily. Hydrology and Earth System Sciences, 15(1): 323-331. https://doi.org/10.5194/hess-15323-2011

VOGEL, R.M.; FENNESSEY, N.M. 1995. Flowduration curves II. A review of applications in water resources planning. Water Resources Bulletin, 31(6):1029-1039. https://doi. org/10.1111/j.1752-1688.1995.tb03419.x

WASEEM, M.; AJMAL, M.; KIM, T. 2015. Ensemble hydrological prediction of streamflow percentile at ungauged basins in Pakistan. Journal of Hydrology,
525: 130-137. https://doi.org/10.1016/j. jhydrol.2015.03.042

WOLFF, W.; DUARTE, S.N.; MINGOTI, R. 2014. Nova metodologia de regionalização de vazões, estudo de caso para o Estado de São Paulo. Revista Brasileira de Recursos Hídricos, 19: 21-33. https://doi.org/10.21168/ rbrh.v19n4.p21-33

YU, P.S.; YANG, T.C.; WANG, Y.C. 2002. Uncertainty analysis of regional flow duration curves. Journal of Water Resources Planning and Management, 128(6): 424-430. https:/doi. org/10.1061/(ASCE)0733-9496(2002)128:6(424)

ZHANG, Y.; VAZE, J.; CHIEW, F.H.S.; LI, M. 2015. Comparing flow duration curve and rainfall-runoff modelling for predicting daily runoff in ungauged catchments. Journal of Hydrology, 525: 72-86. https://doi. org/10.1016/j.jhydrol.2015.03.043

\section{Endereço dos autores:}

César de Oliveira Ferreira Silva - Departamento de Engenharia Rural, Faculdade de Ciências Agronômicas, Universidade Estadual Paulista (UNESP), Campus de Botucatu, Avenida Universitária, $n^{\circ} 3780$, Altos do Paraíso, CEP: 18610-034, Botucatu, SP, Brasil.E-mail: cesaroliveira.f.silva@gmail.com

Rodrigo Lilla Manzione - Departamento de Engenharia de Biossistemas, Faculdade de Ciências e Engenharia de Tupã, Universidade Estadual Paulista Júlio de Mesquita Filho, Rua Domingos da Costa Lopes, 780, Jardim Itaipu, CEP: 17602-496, Tupã, SP, Brasil. E-mail: lilla.manzione@unesp.br

Artigo recebido em 25 de março de 2020, aceito em 23 de julho de 2020. 